Revista Iberoamericana, Vo1. LXXXIII, Núm. 258, Enero-Marzo 2017, 41-55

\title{
BUENOS AIRES COMO PRISIÓN - PARAGUAY COMO UTOPÍA: FORMAS DE RESISTENCIA Y LA CREACIÓN DE ESPACIOS ALTERNATIVOS EN LEONERA (2008) Y EL NIÑO PEZ (2009)
}

POR

Ana Luengo

En la primera década del siglo XXI se estrenaron dos películas, Leonera de Pablo Trapero y El niño pez de Lucía Puenzo, que comparten unos elementos significativos tanto en la historia como en la disposición fílmica. Lo que más llama la atención es que en ambas películas se narran las historias de mujeres que desean abandonar Buenos Aires y que huyen a Paraguay para comenzar una nueva vida. Sin embargo, ésta no es la única semejanza: de entrada, ya podemos ver que los títulos aluden al mundo animal, y que ambas películas comparten rasgos del género policial: un crimen por resolver, un entorno carcelario, suspense, una estética de autenticidad, una forma de resistencia. De todos los rasgos, este último es el que más me interesa, pues ambas películas sirven como mediadoras para dar a conocer unas historias no siempre visibles, creando así una "instancia solidaria" (Voionmaa) que conecta la historia fílmica con la sociedad que representa y para la que se produce.

Por otra parte, la huida a Paraguay nos remite al experimento de Macedonio Fernández a principios del siglo pasado. Sin perder este dato de vista, me propongo analizar cómo se configura el espacio utópico en la actualidad y cómo se inserta en una conflictiva temporalidad narrada -y en parte silenciada. Además, esto nos lleva a la cuestión de cómo este Paraguay estilizado se contrapone a la representación fílmica realista de un Buenos Aires que se ve y se vive como centro en tensión violenta con lo otro y consigo mismo. Con el fin de entender a qué se debe esta oposición, en este artículo se va a analizar el espacio que ocupan las protagonistas en Buenos Aires para ver qué les impulsa a la huida hacia ese otro país tan deseado tras una frontera incierta. Al contrario del Buenos Aires del fotógrafo Russell, del libro El último lector de Piglia, quien reproduce en una maqueta al detalle la ciudad que recuerda o imagina -lo que viene a ser casi lo mismo-, en estas dos películas la representación de la ciudad se asocia a espacios precisos que la ciudad en sí contiene, pero que aparecen de forma desarticulada, lo cual no permite la visión de la ciudad a vista de pájaro. Esto me parece fundamental pues infiero en ambas películas un intento de posicionamiento 
en una discusión política de mayor dimensión, que tiene que ver precisamente con el espacio vulnerable que ocupa la mujer en la sociedad latinoamericana. Porque digamos, retomando a Vattimo, que sin la panorámica, sin la maqueta que abarque el todo, el individuo no puede ver ni el espacio físico ni el espacio social que ocupa, lo que le fuerza a su propia desorientación y le resta capacidad de agencia, por lo que la elección de una perspectiva, de una visión y de un encuadre son definitivos. Es decir que, sin el contexto, "nos movemos en un espacio sin horizonte" (Vattimo 32). Para ubicarnos, necesitamos, siempre, una mirada más amplia y abarcadora, que es lo que intenta lograr Russell al crear su maqueta, y unos límites precisos. Y esto tanto se observa en la mirada de los mismos personajes de las películas propuestas como en la mirada privilegiada por la cámara, la cual es la clave ética/estética central para poder analizar ambas películas. Y que da visibilidad a esa instancia solidaria a la que antes hice referencia.

Para pensar en el espacio que las protagonistas ocupan, voy a retomar algunas de las teorías de Hannah Arendt, de su libro La condición humana, quien describió y analizó la posición social del individuo dentro de la urbe desde una perspectiva histórica. Me parecen necesarias como punto de partida, pues explican el orden en crisis actual por varios paralelismos que iré señalando. En ambas películas se narra la crisis de un sistema social endurecido, neoliberal y reproductor a su vez de estructuras coloniales, en que los personajes subalternos -en general las mujeres- quedan excluidos, por lo que necesitan romper y transgredir los límites impuestos a través de su propia agencia. De ahí la necesidad de cruzar la frontera, de salir del país, de adentrarse en un espacio por descubrir, por re-descubrir, por inventar, por diseñar: Paraguay.

Desde la frontera paraguaya con Argentina y Brasil se pueden ver los espacios como oposición, pues dicen mucho sobre la economía, el desarrollo, la creación imaginaria y política de periferias, lo cual siempre supone la perspectiva y la jerarquización desde un centro autodefinido como tal. Aunque en el caso de Paraguay, que geográficamente es central, esa "periferia" se configura como un contrapunto necesario entre los países aledaños más fuertes, socios también del Mercosur. No es sólo una cuestión simbólica, es sobre todo una cuestión política y económica, pues Paraguay es perfecto como gran bazar y como cantera de mano de obra barata. Todo esto supone que Paraguay, desde la Argentina, pueda parecer a cien años de distancia, como dice el chiste. La cuestión es pensar por qué razón es así, qué llevó a este atoramiento de las estructuras paraguayas. La respuesta es obviamente dolorosa y, por supuesto, vergonzosa: el empobrecimiento de Paraguay es una consecuencia directa de la invasión argentina, brasileña y uruguaya en 1864, con apoyo de Gran Bretaña. Esta guerra fue la responsable del desgaste de las estructuras que hasta el momento funcionaban, dizque mejor que las de otros estados americanos; fue responsable del genocidio de la mayoría de la población, del empobrecimiento masivo del país, de la deuda externa que debió pagar Paraguay a los vencedores hasta los años cuarenta del siglo XX. Y esos países victoriosos fueron los

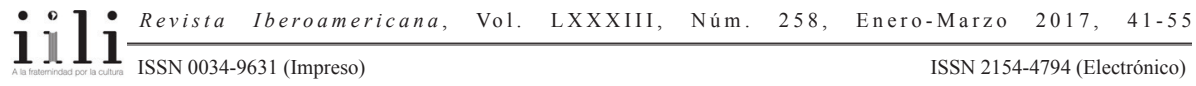


responsables de las fronteras que aún existen, y que siguen recordando impunemente la apropiación ilegítima de grandes terrenos.

$\mathrm{Y}$, a la vez, con la ironía que a veces parece gastarse la historia, todo eso hace que se mantenga la utopía de Paraguay, que naciera ya durante la colonia con las misiones jesuíticas -lo cual es por cierto discutible, pero en parte ha quedado así en el imaginario-, y que llevó a principios del siglo XX a algunos alemanes -entre ellos la hermana y el cuñado de Nietzsche- a ocupar la fértil tierra para crear su Neuland antisemita. Utopía fascista para nosotros desde hoy, por descontado, pero utopía para aquéllos en esos días, al fin y al cabo. Por otra parte, el estado de precariedad en que queda el estado paraguayo, y que arrastra, también es un ingrediente fundamental para la utopía contemporánea: tierra aún pura, tierra aún verde y roja, tierra aún por descubrir, por construir, tierra originaria a la que volver. Tierra en el corazón de América del Sur, que es además productora de oro verde.

\section{EL NIÑO PEZ Y LOS ESPACIOS ALTERNATIVOS DE LA RESISTENCIA}

En El niño pez se narra la historia de dos adolescentes que planean escapar a Paraguay. Una es una chica bonaerense rica, Lala, y la otra su sirvienta paraguaya, La Guayi o Ailín. Para conseguir dinero para construir una casa en Paraguay, les roban obras de valor a los padres de Lala, que luego ellas revenden a traficantes. La relación entre Lala y Ailín dentro de la casa está condicionada por tres elementos: en primer lugar, por la subalternidad de Ailín, quien trabaja como sirvienta desde los trece años y proviene de Paraguay. En segundo lugar, ambas chicas tienen relaciones sexuales, lo que, en cualquier caso, las sitúa en un lugar clandestino y vulnerable. En tercer lugar, la representación de la ciudad está fragmentada, por lo que parece que pudieran estar tanto en Buenos Aires como en Santiago de Chile, Madrid o México D.F. a causa de ese desmembramiento que antes señalé, y de que se privilegian los espacios interiores, por lo que éstos requieren un análisis pormenorizado. Sobre esta fragmentación de la gran ciudad, Botana señala con acierto:

La megalópolis conforma así un nuevo feudalismo con sus protecciones recíprocas, sus ejércitos privados de seguridad, su tecnología adaptada a un terreno que, para desdicha de Rousseau, sólo tiene en común aquello que pertenece a un grupo en particular. Este cuadro de violencia - una suerte de imagen del mundo de Hobbes tal como él lo concebía, fragmentado en porciones territoriales- es tributario de las desigualdades y de una onstentible falencia de las instituciones del Estado de derecho. (Botana 59)

De esta forma, la estructura del hogar, como la fragmentación menor de este "nuevo feudalismo", coincide con el oikos que describiera Hannah Arendt. Para ello, debemos retomar brevemente la distinción entre las dos esferas, la privada y la pública:

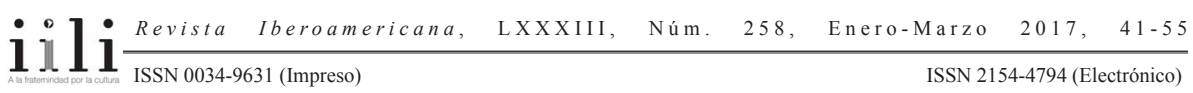


en la esfera privada, el llamado oikos, era donde la familia satisfacía sus necesidades vitales y servía para la perpetuación de la especie; en la pública, que era la polis, era donde el hombre que poseía un hogar podía hacer valer sus derechos y cumplir con sus deberes para la sociedad. Y escribí "hombre" a sabiendas porque es central en el desarrollo de la trama de El niño pez, al ser el padre quien ostenta el poder y quien se impone al resto de personajes de forma violenta. En la película se puede presenciar entonces, por la disposición de los espacios físicos, cómo se marca la estructura de la esfera privada, mientras que de la pública apenas nos llegan resonancias por los comentarios de otros personajes o por los medios de comunicación. En ambos casos, presenciamos la paulatina degradación del hogar a partir de los sutiles gestos de agencia de los hijos, de la sirvienta y de la esposa, y la violenta impotencia del padre al no poder mantener el poder hegemónico como respuesta. Finalmente, la muerte de Bronte, envenenado por su hija Lala, impulsa la disolución del orden patriarcal establecido, y la acción en la trama.

El padre, el déspot y dueño del oikos, es un juez reconocido, autor de libros, pero podemos ver ya desde el principio que, aunque la esfera privada esté prácticamente subyugada a él, está en estado de descomposición, lo que se refleja materialmente por la extracción de las obras de arte y otros modos de agencia, en una suerte de toma de la casa. El robo podría ser el primer acto de resistencia, pues su hija y la empleada están robando su propiedad desde el interior para poder financiar la compra de la casa en el Paraguay, que parece el leit motiv de su relación. El segundo acto de resistencia será el asesinato del juez envenenado por su propia hija tras sorprender a Ailín abrochándose la bata, después de tener relaciones sexuales con él -queda por discernir si ha sido forzada a ello o no-, lo que da lugar al suspenso. Este crimen es lo que provoca la huida de la hija a Paraguay y el encierro de la sirvienta como sospechosa del crimen en un centro penitenciario de menores. El tercero será el cambio de imagen de Lala, que de rubia adolescente pasa a metamorfosearse en una heroína andrógina, lo que pretende invertir los papeles en la relación entre las chicas. En una suerte de peripecia trágica salva a Ailín, la princesa, de las fauces del dragón, el comisario que la prostituye cuando está interna en el centro penitenciario de menores. El cuarto acto de resistencia es más polémico y ambiguo, y su agente es la propia Ailín, quien funciona como motor del resto de la trama, por lo que lo trataré más adelante detenidamente.

Volviendo a la relación entre las chicas, elemento central y articulador de toda la historia, lo más importante es que está abocada a la clandestinidad, por la ya referida relación de subalternidad de la Guayi, por su origen (Ypacaraí), por su clase social, por su pasado, y por el lesbianismo. De esta forma el sueño de ir a Paraguay, de decir en guaraní las palabras de amor bonitas y tiernas, es lo que parece unirlas. Ellas están en Buenos Aires, pero es interesante que Buenos Aires no se represente apenas, lo que corrobora esa sensación de ilocalizabilidad a la que antes hice referencia. Los espacios

$111 \frac{\text { Revista Iberoamericana, Vol. LXXXIII, Núm. 258, Enero-Marzo } 2017, \quad 41-55}{\text { ISSN 0034-9631 (Impreso) }}$ 
acostumbran a ser cerrados, y los únicos trayectos se llevan a cabo en el ciclomotor de Lala y de su hermano, rompiendo la sensación de continuidad física entre unos y otros lugares, lo que propone una representación fragmentada de la geografía urbana, arrebatándole así todo elemento identitario y convirtiéndola en "cualquier gran ciudad". En El niño pez Ailín no tiene acceso a conducir el vehículo, solo puede ir de acompañante de Lala, quien sí puede moverse libremente y tener el control hasta el final en ese Buenos Aires desmembrado. Los espacios de control para Ailín son otros y tienen que ver con lo sensual: la fiesta, el concierto, cuando puede bailar o cantar, y sobre todo el sexo, siempre en espacios cerrados y concretos, y aquí es cuando resulta interesante fijarse en el cuarto acto de resistencia que ella lleva a cabo durante toda la historia según mi interpretación. Ailín es la sirvienta del hogar y está subyugada al poder de todos los otros habitantes, por ello su forma de agencia ha de ser más sutil, y no está claramente representada, pero se puede detectar en una observación del personaje a contrapelo. Fijémonos en que Ailín sólo tiene voz cuando ambas amantes aparecen encerradas y están enteramente solas en lo más recóndito de la esfera privada del juez. Esa voz se materializa en el uso del guaraní. Ella es la única que domina esta lengua que de por sí supone una historia de resistencia. Uno de los momentos más íntimos es cuando las dos chicas se bañan juntas, y Ailín le enseña a Lala cómo hablar la lengua del pueblo originario, invirtiendo la impuesta jerarquía que presenciamos fuera de ese espacio. Para Lala, el amor de ambas no ha de soportar - pues no le está permitido- la exposición en la esfera pública, y llega a su felicidad (y libertad) sólo entre cuatro paredes, que en la escena se marcan por la presencia de una mampara que bien podría simbolizar ese otro espacio aun más reducido de la intimidad. Agamben, siguiendo a Aristóteles en Ética a Nicómaco, señala que el placer sería la única experiencia esencial para el humano, en la que podría hallar su fundamento una nueva concepción del tiempo y una conciencia de ser (153). Desde ese sentimiento, Lala se abre a los deseos de Ailín. Pero ésa tampoco puede ser la salida a largo plazo si hablamos del espacio social, del equilibrio entre el zoé y el bíos (González): optar por la mayor intromisión, el ensimismamiento, el encierro en espacios cada vez más reducidos, que igualmente han de provocar un estancamiento, y que no permiten a la ciudadana formar parte de la urbe, es decir, acceder plenamente a sus derechos, ser zoon politikon. Además, hasta el amor, el deseo, el erotismo, son también actos políticos y están sujetos a reglas sociales, y a un imaginario que varía y evoluciona dentro o fuera de unas leyes y unas normas, y dentro de las ficciones y también a partir de ellas, que generan y se convierten en realidad. Las bodas como copias de otras bodas de catálogos y películas, y el sexo como reflejo de imágenes vistas y de fantasías aprendidas en otros lugares que consideramos arte o pornografía, lo que de nuevo es una revaloración de lo representado. Lala está descubriendo un mundo que no cree ya habitado, está cruzando el espejo, por usar la metáfora de de Lauretis. Ailín necesita impulsar a la chica rica para que ésta rompa el

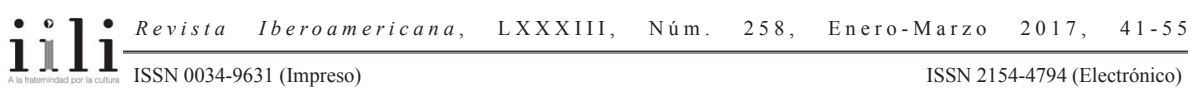


resto de límites de su encierro, que es mucho más complejo pues es también social, cultural, étnico, económico, sexual. Lala y Ailín sueñan juntas por esa razón con escapar del claustrofóbico encierro, y con construir esa casa en Paraguay como una promesa de felicidad futura: acaso el placer les ha dado la conciencia de ser-ahí, o le ha dado la conciencia a Lala, quien ha descubierto qué es el placer. Porque el sueño es de Ailín, el destino lo elige Ailín, la forma de acceder a la huida también la planea Ailín. Así, de forma ingenua, un Paraguay ideal se configura para Lala como un espacio utópico donde alcanzar la libertad para amarse y huir de la agobiante familia patriarcal, que aparecería como sinécdoque de la mega-ciudad.

La adaptación cinematográfica de la novela de Puenzo debe ser la historia de muchos sacrificios, pues aquella es una novela compleja en todos los niveles. La novela transcurre en gran parte en un Paraguay poco idealizado, donde la corrupción social llega a una estética grotesca y expresionista. En cualquier caso, el mundo narrado es obsceno y cruel, con el pequeño espacio como refugio en la casa de Charo, el abuelo de Lin (Ailín en la película), quien es un personaje casi inverosímil por su pureza y bondad en el centro de ese torbellino destructivo. Recuérdese la cena que ha de sufrir Lala en casa de Socrates -sin tilde-con la crème de la crème paraguaya, la narración del descubrimiento de Socrates como actor mientras tenía sexo con una Lin púber que quería darles calor a todas las crías de la naturaleza dentro de su vagina. Y otros tanto elementos irritantes: la presencia de las familiares cercanas del actor trabajando para él como criadas y disfrazadas como tales; los perros vomitando sobre la mesa; la joven modelo haciéndose saltar los dientes para no tener que emigrar y poder, sin embargo, acostarse con el famoso y decadente Socrates. O, de forma simbólica, los ataques y maltratos a Serafín, el perro narrador de la novela, otro acierto que se debe sacrificar en la pantalla. Pero en la película la complejidad se reduce y se materializa en los cronotopos entrelazados: por una parte el viaje de Lala a Paraguay, posterior al asesinato del juez, y su vuelta, y por otra los sucesos anteriores en Buenos Aires. Y al final se unen ambas líneas del relato que destacan el rompimiento de un orden hasta entonces mantenido. La fractura de éste se da cuando Lala huye a Paraguay, después de envenenar a su padre al creer que él está abusando de Ailín. Según Drucaroff ella se va a suicidar, pero él se adelanta tomando la leche. Sin embargo, en la película su comportamiento es muy ambiguo, pues Lala es muy hermética. Aunque en la película se privilegia su perspectiva, apenas alcanzamos a imaginar qué piensa, sólo qué percibe o cree percibir. Por otra parte, Ailín es un personaje con un gran poder de seducción, como en la novela se explicita al mostrar que ella vive el deseo sólo por la mirada ajena, aunque sea su propia mirada, lo que sin duda es una suerte de erotización de Ailín para el resto de personajes, que tiene que ver con la representación colonialista de la mujer indígena desde la Conquista. Este comportamiento de Ailín, quien para conseguir su propósito tanto enamora a Lala y a su padre, como al adiestrador de perros, que a la

$111 \frac{\text { Revista Iberoamericana, Vol. LXXXIII, Núm. 258, }}{11}$ Enero-Marzo 2017, $41-55$ 
vez es el traficante de las obras robadas, significa un fenomenal conocimiento de las únicas herramientas que le quedan. Para este comportamiento, hay otro aspecto que me interesa: "Cuando las personas están sometidas a esa vida de sumisión, la única forma de liberarse es someterse a otras y obligarlas, con violencia, a que las liberen" (Niggemeyer 26). En la novela, el perro narrador afirma en un momento: "Y yo supe que era la Guayi la que nos manejaba a todos. A los Brontë y al mundo. Y que si afuera llovía es porque adentro la Guayi lloraba" (26), lo que me parece una clave importante para entender el personaje también en la película, pues marca de nuevo esa diferencia entre ambas esferas: afuera/adentro. Lo destaco pues creo que esa ambigüedad en Ailín es central, y por ello es llamada por dos nombres en la película: la Guayi y Ailín, que tienen connotaciones muy diferentes. La Guayi por ser una sirvienta paraguaya, y Ailín que es un nombre mapuche -que no guaraní- que significa la clara. En la novela, sin embargo, Guayi es el apodo que el perro le da, y el resto de personajes la llama simplemente Lin. Igualmente en la película todos los personajes centrales se desdoblan: el juez es una autoridad moral en la esfera de lo público, pero amoral en la privada; el padre idolatrado de Lin es galán televisivo y a la vez padre abusador, y la misma Lala aparece tanto como chica rica y mimada, como heroína de thriller armada con una pistola, entre otras cosas. Pero sin Ailín no habría película, así como sin Lin no tendríamos novela. La cuestión es por quién accedemos a ella en la película.

Lala viaja en autobús hasta la frontera tras envenenar a su padre, después de descubrir que ha tenido relaciones sexuales con Ailín. En el viaje se introduce un nuevo enfoque, pues ya no se trata de un espacio cerrado urbano, y por ello el plano permite más holgura, más luz, otros sonidos. En la escena en la frontera con Paraguay, la realidad que percibimos como espectadores es la realidad que se representa siguiendo una estética de autenticidad (Funk 13). Así se muestra el espacio con unos deícticos reconocibles-el mercado, la música, los colores-, que muestran la frontera con Paraguay por fin claramente reconocible, y también como "más latinoamericana", no sólo por los referentes escogidos, sino también por el ritmo que crea el paseo de Lala, señalando la existencia de esa otra velocidad tan pausada y tan ajena a sus paseos en ciclomotor por Buenos Aires. De nuevo esa distancia de los cien años que recuerdan un viaje a la inversa de la modernidad, o la otra cara del neoliberalismo: el mercado en un lugar preciso fronterizo. El dispositivo usado crea tal efecto de veracidad, pues se representa como si fuera la imagen de lo otro desde la mirada de una turista, la misma Lala, que meses antes bailaba la música distorsionada que ahora oye en el mercado, pero que lo hacía en su hogar bonaerense gracias a un buen equipo de música. Es decir que se da una renegociación entre dos mediaciones de la realidad: una es el descubrimiento de Lala, quien camina aturdida entre los vendedores haciendo tiempo hasta que salga su autobús; la otra es la realidad representada en los documentales de viajes, que intuimos como palimpsesto y busca crear un efecto de identificación con la protagonista para un

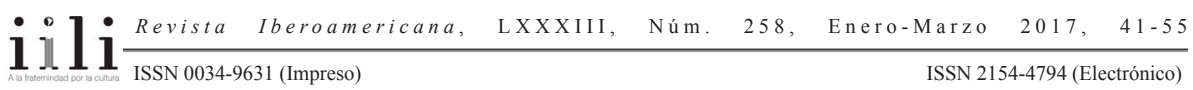


público internacional. Sin embargo, cuando Lala llega a la casa de Ailín, lo auténtico da paso a lo mítico, al espacio maravilloso, introduciendo la leyenda del niño pez que le da título a la película: el bebé que Ailín tuvo de adolescente y ahogó en el río. Pero es importante destacar que se accede por la mirada de Lala, quien fascinada por Ailín y por ese entorno en otro espacio-tiempo, dota de ese significado a la superstición del pueblo, y rememora las palabras de su amante en Buenos Aires, percibiendo el entorno a partir de la propia narración de una Ailín ausente. Lo que en este punto es determinante, y acaso enlace con el dispositivo de autenticidad que anteriormente señalé, es que precisamente ese paso por la frontera desde la mirada de Lala dota a ella, a su conciencia, de una centralidad importante. Si en la novela vemos y oímos por la narración de Serafín, perro simbiótico con las dos chicas; en la película es Lala quien nos permite creer en un Paraguay inexistente por su mirada asombrada, sea ante una realidad verosímil -casi de documental de viajes- o ante una maravillosa, mucho más poética o pictórica que apunta a una percepción sensible y onírica. Pero esa mirada de Lala sólo es posible por la influencia de Ailín entre esas cuatro paredes en la casa de Buenos Aires. La escena del niño pez casi le podría dar movimiento a un cuadro surrealista de Marc Chagall. Aunque Lala sea parte de él, y por su socialización podría detectar esa belleza de ver el azul como si nunca hubiera estado allí. Nosotros, el público, también podemos percibirlo así. De esta forma, Lala, desde dentro, impone su mirada y su experiencia creando una complicidad que debería seducirnos a verlo a través de ella, personaje privilegiado.

Cuando Lala se entera de que Ailín está en un instituto de menores arrestada como sospechosa por la muerte del juez, vuelve a Buenos Aires para salvarla. La prisión afectiva que era el hogar del juez, se convierte en prisión real para Ailín, quien no tiene ni siquiera la presunción de la inocencia por su origen y por su posición social. En Buenos Aires Lala se corta el pelo en la tina donde antes se bañaba con Ailín, con lo que, según Punte, comienza una dinámica de travestimiento para tornarse en objeto de deseo lésbico. Pero yo creo que hay más: simbólicamente, Lala retoma el mismo espacio de intimidad para llevar a cabo un acto que la impulsa de veras a romper con esa esfera privada, y asimismo con una de las más importantes convenciones sociales burguesas: perder su melena rubia, es decir, el símbolo de una forma de feminidad basada en una estética clásica y europeísta de la belleza, lo que es una despedida de la imagen de la princesa triste y una reivindicación de su propia sexualidad. Pero también es retomar el mito de Samsón a la inversa. Este rito iniciático tiene fuerza en la pantalla por el primer y primerísimo plano, y por el silencio sólo interrumpido por el ruido de la tijera. Aunque en la película no es tan impactante como en la novela, en que se afeita la cabeza y se arranca las cejas para volverse como un dibujito de esos japoneses. De esta forma, va a visitar a su novia al centro de menores, y ésta le dice que la deje en paz invirtiendo así los papeles al cambiar de espacio: de la propiedad

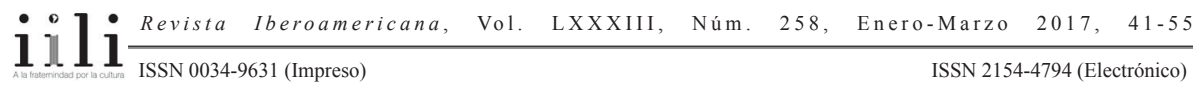


privada de la familia de Lala, al espacio de la cárcel donde Ailín ya no es la Guayi, aunque es más Guayi que nunca pues se le ha arrebatado cualquier derecho. Ailín se torna homo sacer, siguiendo a Agamben, es decir, sólo cuenta con la vida desnuda no protegida por la ley. Su único derecho es el desprecio por su amante rica e impune que se ha metamorfoseado para ella. Al final, Lala salva a Ailín de una orgía en casa del comisario, adonde envían a las adolescentes encarceladas, previamente maquilladas y arregladas, por supuesto. Ailín ha sido vendida a un matrimonio maduro que acaba tomando un rol burgués y pacato cuando es sorprendido en tal bochornosa escena. Este momento en que Ailín va a ser víctima de los abusos sexuales de esta pareja rica, marido y mujer burgueses, indica la condición de subalternidad y resignación sexual a la que la chica ha estado siempre sometida por su clase, su origen y su género. En una escena de acción, propia del policial, con tiroteos y demás, Lala salva a su amada, re-tomando así las riendas, como cuando ella era quien manejaba el ciclomotor en sus momentos de felicidad. Y así, ellos tres, Lala, Ailín y Serafín, huyen a Paraguay. Happy Ending. O no, acaso el final de esta ficción, y el apremio a seguir generando realidades alternativas.

Dicen las protagonistas mirándose a los ojos:

Lala: ¿Es un final feliz?

Ailín: No lo sé.

Lala: Inventa.

En la película aun queda la esperanza de ese amor en el que ya nos cuesta creer. Con la metáfora del lago mítico, la imagen final nos remite a un final abierto y acaso dulce. No así en la novela, donde sabemos que Lala va a morir, y que esa mirada tierna es sólo un rescoldo de la nostalgia o ternura por la felicidad pasada. No hay amor que cien años dure ... Pero Ailín sí va a poder huir de su cautividad finalmente, sea adonde sea.

\section{LEONERA: LA TOMA DE CONCIENCIA ENTRE REJAS}

En el caso de Leonera de Trapero, que se estrenó un año antes, encontramos un tratamiento diferente, pero con algunas semejanzas a tener en cuenta, de los espacios que ocupan los personajes. La película comienza precisamente in media res, con Julia despertando en su casa cubierta de sangre, tras lo cual se ducha y va a la universidad. Sólo a la vuelta parece darse cuenta de qué ha pasado, y desesperada llama por teléfono a alguien. La policía llega y Julia es encarcelada como sospechosa del crimen. Ese hilo de la trama queda sin solucionar, pero reconstruirlo con toda su complejidad tampoco es lo importante para este trabajo porque ni siquiera hay nada concluyente. A grandes trazos la historia se puede resumir así: Julia estaba estudiando, y convivía con dos hombres. Ella había quedado embarazada de uno de ellos, pero ellos vivían a su costa y

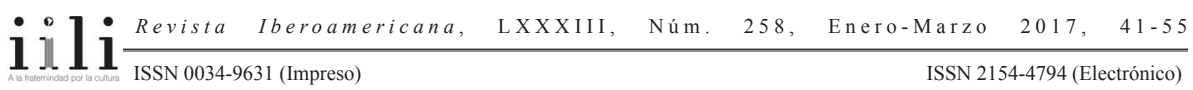


tenían una relación sexual entre ellos que la había empujado al margen, aunque vivían en el departamento de la madre de Julia. Los hombres le habían arrebatado de esa forma hasta la cama, y sumido en un estado de apatía. Como se ve, de nuevo la reescritura del motivo de "Casa tomada" de Julio Cortázar, o un aliciente para pensar desde el principio en espacios ocupados, lo que acaso sea más relevante. Arendt señalaba que lo que no permitía a la polis violar las vidas privadas de sus ciudadanos era que sin una casa un hombre no podía participar de los asuntos del mundo, con lo que se creaba un equilibrio, o un compromiso (42). Julia ha perdido esa categoría doblemente, como mujer y como excluida, estado en el que cada vez se hunde más hasta el final, pues Julia ya no vuelve a ser una ciudadana y ocupa esa turbia condición de homo sacer también. Ni siquiera tiene voz: el abogado le escribe cómo y qué debe testificar, y en el juicio no la dejan hablar libremente, y en cuanto lo hace, la interrumpen y silencian.

En esta película se representa uno de los espacios más problemáticos del cine argentino contemporáneo -y de la realidad, claro-, lo que alude implícitamente al trauma de la última dictadura militar, mas desplazado cronológicamente: el embarazo y la maternidad en la prisión. El momento histórico es otro, pero la incomodidad sigue ahí, agazapada en el fondo de un trauma insuperable. En Leonera Julia tiene a su hijo en ese entorno, en un parto durante el cual la atan de pies y manos con correas. Julia debe cargar a su bebé recién nacido con las manos esposadas, y está obligada a criarlo en un microcosmos donde las relaciones tienen unas normas que ella debe aprender. Así, su compañera Marta le pregunta: “Vos no sos de acá, ¿por qué estás acá?”, dotándole al espacio de un significado no físico, sino social, y acaso temporal. Julia así se torna la extranjera en el cronotopo carcelario, que es el de su propia ciudad. Finalmente Marta la guía en ese nuevo mundo, la ayuda con el bebé, hasta amamantándolo para tranquilizarlo, la cuida a ella, se acaban queriendo y convirtiendo en amantes. Aquí se puede retomar la observación de Tacetta y Peña, cuando indican que el espacio carcelario se ha tornado un motivo casi necesario al tratar el amor entre mujeres (116). Por otra parte, y según Arendt: "En la esfera privada de la familia era donde se cuidaban y garantizaban las necesidades de la vida, la supervivencia individual y la continuidad de la especie" (56), lo que me parece significativo. Así Marta, quien ya tiene una posición pública en ese espacio periférico aunque insertado en la ciudad, cumple esa función y la introduce también a ella en lo social, es decir, en el espacio de la cárcel. Julia así pasa a ser "de acá".

Los poderes se invierten. En un travelling podemos ver cómo se representa a sus compañeras de prisión cuando la funcionaria pasa lista recorriendo el pasillo: primero apenas vemos partes de sus cuerpos morenos, sus ropas ceñidas de colores, los niños cargados en la cadera, sus vientres distendidos de tantos partos y del poco cuidado. Al final aparece Marta, y su puerta con su nombre escrito en mayúsculas rompe la secuencia. Ahí la identidad de esa otra, desconocida y parte sin visibilidad de la sociedad

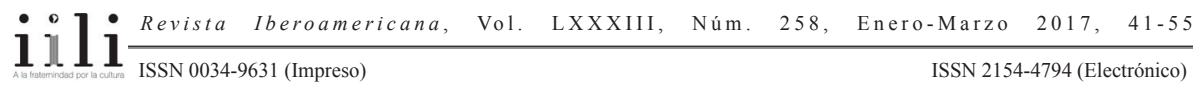


argentina europeizante, toma rostro y forma, configurándose el personaje en individuo central, y proponiendo lo que Labrador Méndez llama un puente empático, como una creación discursiva que es "una tecnología de imaginación política, como algo que permite que se piensen y vean cosas que antes no eran viables, ni pensables" (563). A partir de ahí, y gracias precisamente a Marta, Julia cría a su hijo, y ella misma va cambiando su aspecto físico, de ser rubia, acaba siendo también morocha, vistiendo ropa de deporte, mostrando la panza. Esto parece recordar la función que tuvieron las cárceles hasta el siglo XIX según estudiara Foucault, la de ocultar lo que la sociedad "bienpensante" no quiere ver. De ahí la extrañeza de Julia al entrar en la prisión, y el asco de su madre después al ver a su hija y a su nieto rodeados por esas otras argentinas que no quiere ver. Y esto es muy importante pues ésta es una elección para resaltar otro Buenos Aires del que desearon los liberales en el siglo XIX. Pero la sorpresa es que en la cárcel no todo es sórdido, y la cámara nos lo muestra asumiendo una percepción subjetiva del espacio. Esto se materializa en la presencia de las rejas, que tiene que ver siempre con el estado de ánimo de Julia. Al principio están muy presentes, y después van dando paso a un espacio doméstico donde las rejas apenas aparecen integradas y de refilón. Así se invierte el sentido y vemos cómo la esfera privada y la pública se mezclan creando un lugar donde lo social funciona bajo otras normas. Y, sobre todo, la sociedad de la cárcel, con esas compañeras que al principio le parecían tan otras a Julia, se acaba tornando un refugio ante la amenaza del exterior, que está personificado por la madre de Julia. La unidad maternal cobra de pleno un sentido histórico aunque sea implícitamente: La madre de Julia aparece tras el nacimiento de su nieto Tomás y hace todo lo posible para arrebatárselo e introducirlo de nuevo en la polis, alejándolo de ella. La cárcel se podría ver entonces como un espacio en que, cual una laguna, las leyes y las normas de la polis se suspenden, pero se establecen otras que no coinciden con la Ley por antonomasia que debería ser precisamente la que rigiera la prisión y sus condenas. Agamben define el estado de excepción como una zona de indeterminación entre "dentro" y "fuera", dado que la suspensión del orden jurídico no lo derrumba y la anomia que se instala no está tampoco tan fuera de la norma. La sorpresa es que la representación de la ciudad para Tomás vuelve a estar llena de límites físicos, cristales, rejas, barandillas, ventanas. Es más, esa supuesta esfera de lo público tiene más obstáculos que el espacio carcelario cuando madre e hijo están juntos, invirtiendo extrañamente las nociones de libertad y necesidad, y anteponiendo la vida como zoé a la vida como bios. Por esa razón, podemos ver que es el Buenos Aires representado el que asume al final los motivos de la cárcel, al igual que el sistema jurídico parece en suspenso.

Afuera Tomás vive con su abuela en un bonito departamento, pero el amor no importa: su abuela no le dedica tiempo al niño, sólo le ofrece la propiedad -juguetes, disfraces- como compensación; pero las necesidades vitales e íntimas de Tomás no quedan satisfechas. Por otra parte, Julia comienza a reaccionar al perder a su hijo:

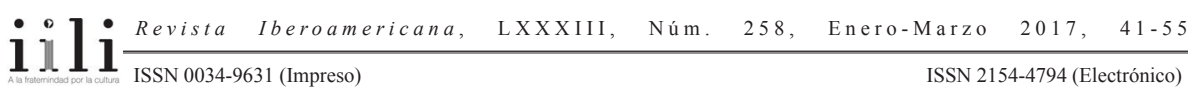


primero por el estallido de rabia frente a su madre ante la injusticia de la apropiación, por lo que es duramente castigada, aislada, despojada de todos los derechos. La prisión, así, se muestra en todo su apogeo, y recuerda lo que escribiera Foucault en su libro de Surveiller et punir, un verdadero conjunto de procedimientos para dividir, controlar y encauzar a los individuos y hacerlos así "dóciles y útiles". Pero no funciona, pues si Julia entra en prisión sumida por una apatía terrible, dentro es donde toma las riendas de lo que llamamos agencia, primero ayudada por Marta y luego, a raíz de la usurpación de Tomás, recobra su voz, se corta el pelo -otra coincidencia con la película de Puenzo- y se cubre de tatuajes, asumiendo una estética de resistencia, porque el castigo penitenciario es sobre todo una manera de someter los cuerpos, de dominar las capacidades humanas y de manipular sus fuerzas. Julia se rebela ante eso mientras toma conciencia y dominio de su propio cuerpo.

Julia ocupa entonces un nuevo lugar en el espacio carcelario para reconquistar su derecho como zoon politikon: es decir, persona con derechos y con una voz en la esfera de lo público. También se torna homo faber al trabajar en el campo de la cárcel, al alfabetizar a las presas, destacando de nuevo esa calidad de lo social que es la isotopía central de la película, y que tiene que ver con los movimientos políticos de los sesenta y setenta. Porque intuyo que esas acciones sirven de nuevo para insertar la historia en un contexto geopolítico mayor: alfabetización, lucha social, derechos humanos, inclusión. Un cronotopo como un deíctico que es una toma de posición política, y que le da sentido a la canción infantil con que se abre la película. Una canción que parece ingenua por los dibujos que la acompañan y por las voces de niños, pero que sitúa la realidad argentina en el centro del continente de América del Sur. Argentina se aleja así del ideal liberal centro-europeísta -fuera lo que fuera eso que Alberdi quería decir cuando escribía sus Bases y puntos de partida para la organización política de la República de Argentina en 1852-y materializándose mestiza, latinoamericana, resistente.

Y quizás ésa es la razón que impulsa finalmente a Julia, cuando consigue escapar con su hijo de la gran ciudad. Otro largo viaje en omnibús, hasta la frontera, donde cruzan el río en barca, motivo cargado de nuevo de simbología como una transición, un renacer, una depuración por el agua. Y así entran en Paraguay, por esa verde y frondosa selva, de la mano, como una promesa de felicidad.

CONCLUSIÓN: LA MIRADA PRIVILEGIADA Y EL PRIVILEGIO DEL OLVIDO

La felicidad prometida en la nueva tierra y la posibilidad de adentrarse hasta el fondo de esa nueva vida serían los finales optimistas de las películas. En ambas películas se cumpliría así lo que Pratt llamó la anti-conquista, que sería la idealización, la primitivización, la naturalización y la arcaización de la Otredad, esta vez materializada en Paraguay (17). Pero para eso siempre es necesaria una jerarquización, un punto de vista,

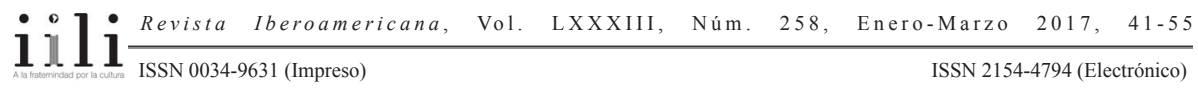


¿desde dónde mirar y qué mirar? (Alba Rico). Finalmente eso siempre es lo determinante. $\mathrm{Y}$ en este caso la mirada es bonaerense. Y privilegiadamente bonaerense, claro, y por eso el puente empático se tiende a partir de Lala y de Julia, pues la identificación para un público potencial urbano se hace más sencilla. Paraguay, como espacio desprovisto de significado histórico, apenas simbólico, se prestaría como posibilidad de retorno a una felicidad originaria no destrozada por los lados oscuros de la modernidad, donde lo íntimo pueda ser parte de lo social, donde la vieja dicotomía entre el zoé y el bíos sea salvable, donde la libertad sea conquistable, donde haya otras velocidades y ciclomotores al alcance de todas y todos. Acaso sí retoman las películas la aventura socialista de Macedonio Fernández tantos años después aun sin saberlo. Pero quizás sea más complicado y estas películas narren el fracaso de la modernidad urbana y de la creación de una esfera republicana (me refiero a la res pública). En las películas que aquí estoy interpretando se narra la crisis de lo público, y la necesidad de encontrar un nuevo modo de construir un mundo mejor que se aleje de un modelo neoliberal en estado crítico. Y por ello el uso de la sinécdoque en ambas películas para hablar de la megápolis corrupta y claustrofóbica es importante: la cárcel y la casa familiar.

Paraguay sería el lugar donde poder levantar esa otra casa, ese otro espacio social, que permita a sus habitantes ser parte de la polis y tener de nuevo derechos, y voz y acceso a la libertad. Un tiempo-espacio donde las velocidades no sigan las directrices del neoliberalismo agresivo, donde nadie quede rezagado pues la selva permite la inclusión y felicidad de todos los seres, donde nadie tenga que dejarse llevar en un ciclomotor que no le pertenece (Martín-Cabrera y Voionmaa 69). Un cronotopo donde el zoé pueda incluirse en la polis, pero no en el marco de exclusión inclusiva en que sí ha estado desde el principio de los tiempos. Pues decidir que una mujer o un esclavo -y qué sería si no ambas cosas esa Guayi que entró a trabajar con trece años de criadano pertenece a la polis, ya es en sí una forma de incluirlo en ella, paradójicamente. Una reivindicación del zoé, como vemos en ambas películas, es una conquista de derechos, es la forma de conseguir que zoé y bios entren en una zona de indistinción que haga posible la realización de todos los individuos, sobre todo de aquellos a los que la ciudad expulsa de su centro, a quienes el sistema político silencia y oculta, a los que no queremos o podemos ver, y que estas películas iluminan. En cualquier caso se trata de cruzar esa frontera geopolítica, natural, ideal, como quien pudiera pedir otra oportunidad para hacer las cosas mejor. Crear así imaginarios alternativos a partir de una instancia solidaria que un público urbano, internacional y sensible pueda entender y hacer suya. Y tengo que pensar en la novela Entre Marx y una mujer desnuda:

Todos somos aquí cómplices de los culpables, y el primer paso para tomar conciencia de nuestra vergüenza y lavarle a la patria su ropita, es decirlo a gritos, armar el gran despelote, como quien pone una bomba y ni siquiera corre antes de que estalle: quizás

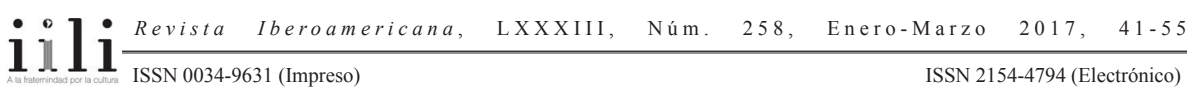


haya una pareja joven, mejor que nosotros, que sobreviva y vuelva a poblar esta tierra que no hemos sabido merecer. (Adoum 283)

Una madre y un niño de la mano en Leonera. Dos mujeres jóvenes con un perro en la adaptación de El niño pez. Nuevos comienzos en una tierra de nadie, en una tierra sin nada: un no-lugar hacia el futuro. La esperanza es una isla utópica en el puro centro de América Latina, donde poder alcanzar la felicidad pues "reinan unión e igualdad" y el pasado, si acaso, es mítico y, por eso, el presente no existe y el futuro es incierto. Y, para ello, como acostumbra a pasar, se borra de un plumazo cualquier reflexión sobre por qué Paraguay está a cien años de distancia de Buenos Aires. Si es que lo está.

\section{OBRAS CITADAS}

Adoum, Jorge Enrique. Entre Marx y una mujer desnuda. México DF: Siglo XXI, 1976. Agamben, Giorgio. State of Exception. Chicago: Chicago UP, 2005.

Infancia e historia. Destrucción de la historia y origen de la historia. Buenos

Aires: Adriana Hidalgo Editora, 2007.

Alba Rico, Santiago. Capitalismo y nihilismo. Dialéctica del hambre y la mirada.

Madrid: Akal, 2007.

Arendt, Hannah. La condición humana. Barcelona: Paidós, 1998.

De Lauretis, Teresa: Alice Doesn't: Feminism, Semiotics, Cinema. Bloomington: Indiana UP, 1984.

Drucaroff, Elsa. Los prisioneros de la torre. Política, relatosyjóvenes de la postdictadura. Buenos Aires: Emecé, 2011.

El niño pez. Lucía Puenzo, dir. Wanda vision, 2009.

Foucault, Michel. Surveiller et punir. Paris: Gallimard, 1975.

González, Carina. "Migración y oralidad: la vida animal en la novela El niño pez de Lucía Puenzo". Revista de Crítica Literaria Latinoamericana 74 (Lima/Boston, 2011): 193-219.

Labrador Méndez, Germán. "Las vidas subprimes: La circulación de historias de vida como tecnología de imaginación política en la crisis española (2007-2012)”. Hispanic Review (2012): 557-81.

Leonera. Pablo Trapero, dir. Matanza Cine, 2008.

Martín-Cabrera, Luis; Voionmaa, Noemi Daniel. "Class Conflict, State of Exception and Radical Justice in Machuca by Andrés Wood." Journal of Latin American Cultural Studies 16 (2007): 63-80.

Niggemeyer, Lars. Gesellschaft und Freiheit bei Hannah Arendt. Ein Vergleich mit Karl Marx. Köln: Papy Rossa, 2008.

Piglia, Ricardo. El último lector. Barcelona: Anagrama, 2005.

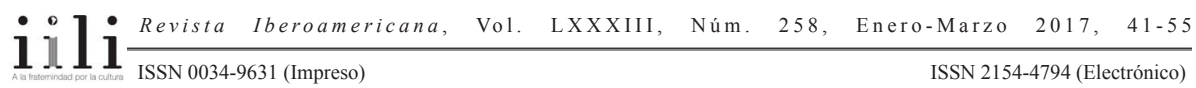


Pratt, Mary Louise. Ojos imperiales: literatura de viajes y transculturación. Buenos Aires: Universidad Nacional de Quilmes, 1997.

Puenzo, Lucía. El niño pez. Buenos Aires: Beatriz Viterbo Editora, 2004.

Punte, María José. "La mirada tras el espejo: para un análisis feminista de El niño pez”. Imagofagia.n.6. (2012). <http://www.asaeca.org/imagofagia/sitio/index. php?option=com_content\& view=article\&id=268\&Itemid=1242012>.

Taccetta, Natalia y Fernando Martín Peña. "El amor de las muchachas". Otras historias de amor. Gays, lesbianas y travestis en el cine argentino. Adrián Melo, comp. Buenos Aires: Ediciones Lea, 2008. 115-132.

Voionmaa, Noemi Daniel. "Con Sangre en el ojo: para una escritura de resistencia”. Amerika (2012): s/p. <http://amerika.revues.org/3389\#bodyftn3>. 
